\title{
The challenge of neuroscience: Psychiatry and phenomenology today
}

From: Psychopathology 35 (2002), 319-326

Thomas Fuchs

Psychiatric Department, University of Heidelberg

\section{Summary}

The paper illustrates the present role of phenomenological psychopathology by outlining its method and focusing on some of its major issues: embodiment or body scheme, intentionality, time-consciousness and intersubjectivity. The application of these categories to the analysis of psychotic disorders is demonstrated. Special emphasis is given to the relationship between phenomenology and cognitive neuroscience, a relationship that has been variously viewed as "mutual constraint" or as "mutual enlightenment". Here a new cooperation linking phenomenology, psychopathology and cognitive science begins to emerge. Phenomenology offers a methodically developed theory of human subjectivity which is indispensable to any attempt to understand, explore and treat psychiatric disorders.

Key words: phenomenology - neuropsychiatry - embodiment - time consciousness - interpersonality - schizophrenia 


\section{Introduction}

The term "phenomenology" is frequently used in psychiatry, but it is still misunderstood as the gathering of "first person data", based on introspective reports, as a raw material for aetiological research $[1 ; 17$, p.148]. However, this "descriptive phenomenology" in the sense of Jaspers stops at half-way; it depicts only catalogues of symptoms and experiences in mental illness [4, 47]. Instead, phenomenology should be conceived as the methodical effort to describe the basic structures inherent in conscious experience, such as embodiment, spatiality, temporality, intentionality, intersubjectivity, etc., and to analyse their possible deviations and derailments. Thus it starts with first-person accounts, but it arrives at substructures of consciousness such as the formation of perceptual meaning, action planning, temporal continuity or implicit memory. It focusses on the form and building-up rather than on the contents of experience. By analysing the modes in which our world experience is constituted, phenomenology is capable of detecting the critical points where this constitution is vulnerable and open to deviations which appear as psychiatric symptoms. By gaining access to the prereflective dimension of experience, the psychiatrist extends his scope of understanding to include phenomena which could otherwise only be taken as bizarre "secretions of the brain".

In what follows I will try to elucidate the role of phenomenology by answering these questions:

(1) Why do we need phenomenology at all in present day psychiatry?

(2) What is the method phenomenology has to offer to the psychiatrist?

(3) Which areas of psychiatry might especially benefit from a cooperation of phenomenology and empirical science?

\section{1) Why do we need phenomenology at all in today's psychiatry?}

Not long ago, an editorial in Biological Psychiatry boldly proclaimed an end of the mind/brain controversy: "Neuroscience has now made it clear that the 'mind' is rooted in the brain”; and: “... we can now safely predict that we shall succeed in understanding how the brain functions and how it dysfunctions" [22]. The biological program with its twin pillars of molecular genetics and neuro-imaging promises to explain the mind either by gene or by brain functions. Biological psychiatrists, neuroscientists, philosophers of mind and eliminative materialists of any prove- 
nance smile at seemingly outdated approaches to mental life via understanding subjective experience. For present philosophers of mind such as D. Dennett there is only a unidirectional relationship between brain mechanisms and personal experience - namely, the latter is entirely produced by the former [9]. Consciousness is a by-product of the brain's activity as a symbol-manipulating machine or an information processor. In this view, the riddles of mental illness will soon be explained by identification of localizable brain dysfunctions and transmitter imbalances. There is no need to rack one's brains about subjectivity and to indulge in the hair-splittings of psychopathology any more.

However, this brave new science suffers from some flaws. First, the subjectivity previously excluded returns by the back door. In neurocognitivist accounts of mental functions the brain is often personalized: It "perceives", "learns", "hypothesizes" and "commands" as if it were a living being of its own. Neuronal circuits are attributed intentional and meaningful behaviour, as if they were some kind of homunculi. To a large extent, neuroscience uses an unreflected "as-if" language. This is only the counterpart of its reductionism: reducing personal consciousness to subpersonal mechanisms results in personalizing these mechanisms. Nearly a hundred years ago Jaspers called this kind of science "brain mythology", and the German psychiatrist Erwin Straus coined a simple sentence which is still true today: „It is man who thinks, not the brain" [41]. The person is the proper subject of experience; and meaning is not somewhere in the brain but only in the interaction between the living human being and its natural and social environment [30].

This leads to a second, more serious objection. Cognitive neuroscience still rests on a passive or "mirror" concept of consciousness [34, p.12; 48]: There is an objective world "out there", and it is represented by images produced inside the brain that become conscious to us. But consciousness has the peculiar characteristic of being inseparably linked to what goes on beyond itself. It is not a passive container or a kind of screen on which the world is projected, but an active, self-organizing process of relating and directing itself to the world. This dynamic and intentional character of consciousness, however, is not covered by the concept of single ,mental events ' that could be translated into corresponding brain states. Therefore the neurocognitive system cannot be grasped separately either; it exists only enmeshed in the world in which we move, behave and live with others through our bodily existence. 
Growing research on neuronal plasticity has made it clear that the brain is not a prefabricated apparatus inserted into the world, but is structured epigenetically by the continuous interaction of organism and environment. The brain is essentially a historical and social organ. Thus instead of representationalism with its fixed inside-outside distinction, we need what Varela [25] termed an "embodied" or "enactive cognitive science" that treats mind and world as mutually overlapping. The recent emergence of a "social cognitive neuroscience" [28] may be a step in the right direction.

This 'systemic' and 'process' view of mental life has consequences for psychiatry as well. If consciousness is not conceivable separately, then mental illness cannot be understood in terms of single, circumscribed dysfunctions, but only as a disturbance of the patient's relation to the world and the others. A "single-symptoms-view" may be useful for criteriological diagnosis, but it loses the holistic level of experience on which the crises and disorders of the self arise. And this argument necessarily extends to the neurophysiological level as well, as Parnas and Bovet have pointed out: Unlike neurologic diseases, psychiatric disorders cannot be related to discrete, localized brain dysfunctions, but rather to malfunctioning interconnections between neuronal modules and their interaction with the environment. They have to be explored on the basis of the continuous self-organization of the CNS as a living system [30].

Now if the 'systemic' view of mental illness is indispensable, then we cannot do without thorough analyses of its first-person experience. For subjective experience is not just an epiphenomenal picturing of underlying 'real' processes, but it is itself an essential part of the systemic interaction of organism and environment. It is only by conscious experience that the organism is able to enter into a relationship with the world on the higher level of meaning, of integrated perceptive and cognitive units or 'Gestalten'; and these meaningful units in turn influence the plasticity, the structuring and functioning of the brain. So when exploring a breakdown in the meaningful relations of a human being with his environment, where could we better start than with his subjective experience itself? Should we not initially set out thoroughly to describe the idiosyncratic way the patient experiences and structures his world? What could better guide us in searching for corresponding neurophysiological dysfunctions than the very sphere in which a meaningful world is originally constituted? 
For these reasons, an adequate science of experience is fundamental for psychiatry as well as for cognitive neuroscience. Without exploring the phenomenology of subjectivity we will not be able to identify the corresponding subpersonal mechanisms. Cognitive neuroscience will remain blind for its proper subject as long as it operates without an appropriate methodological description of what it attempts to explain. Unless we overcome the present objectivistic, reductionist epistemology in psychiatry, empirical research will be seriously impeded. This leads to my second question:

\section{2) What is the method phenomenology has to offer to the psychia- trist?}

A thorough description of the phenomenological method would be beyond the scope of this paper. I will only give a short sketch of some of its basic features:

The starting-point of phenomenology as exposed by Husserl is the discovery that our primordial experience is always hidden by habitual beliefs and assumptions. The essence of experience has therefore to be uncovered by the rigorous abstinence from all taken-for-granted convictions, by a suspension of the so called "natural attitude" to reality. We are requested to put in abeyance what we believe we 'should' think or find, and especially any explanation that derives the phenomena from underlying causes not to be found in themselves. By this systematic disengagement or epoché as termed by Husserl, the phenomenologist arrives at a "bracketing" even of the primordial belief in the existence of the world. As a result, he is able to turn his thoughts and acts into objects of his awareness, instead of being absorbed by their contents as we usually are. The direction of thinking is turned backwards towards the arising of thoughts themselves, towards their transcendental source [43].

This peculiar turn of his attention leads the phenomenologist to a fundamental or 'transcendental consciousness' which constitutes the world and in all its acts constantly refers to it. The world and all its phenomena become a correlate of this intentional consciousness. After this move, in the next step phenomenology aims at the intuition of the essence of the phenomena by imaginative variations which allow their invariants or essential features to appear. These essences have then to be described and translated into common language by an intersubjective process of mutual 
understanding in a scientific phenomenologic community. In the last step, the phenomenologist returns to experience itself - in our case clinical experience - in order to check for the appropriateness of his findings to the phenomena he encounters. By suspending our commonplace assumptions about reality, this whole process of the so-called 'transcendental reduction' leads to a disclosure of the originary underpinnings of our experience. It follows the constitution of self and reality down to the basic structures of corporality, spatiality, temporality, and intersubjectivity.

Now if the psychiatrist undertakes this process of epoché and reduction, he arrives at the prereflective dimension of experience which is affected especially in psychotic disorders. For here consciousness loses its ground in the lived body as the seat of taken-for-granted habitualities; it loses its anchoring in temporal continuity and its rootedness in the intersubjective common-sense [5]. As Blankenburg [3] has pointed out, one could say: What is performed actively by the phenomenologist is suffered passively by the schizophrenic patient, namely a shaking of the natural attitude, an estrangement from the common and taken-for-granted reality. The framework underlying our everyday experience is itself deranged and laid bare. The schizophrenic person suffers what Laing [19] called an "ontological unsecurity". Therefore the way of phenomenological reduction is at the same time the way to come as near as possible to the disturbed processes of constitution in psychosis. Moreover, even in the erosion of the constitutional processes, the patient still strives for a coherent world view, even though this may only be possible in the form of delusion. Phenomenology also explores the modes through which the patient tries to make sense of the basic disturbances and to reestablish some form of coherence [38].

This brief outline of the phenomenologic method has pointed out its special affinity to the core of psychiatric disorders. The resulting mutual dependence between phenomenology and empirical research is one of the hot topics in today's debate in psychopathology [15, 35, 42]. This leads to my third question: 


\section{3) Which areas of psychiatry might especially benefit from a coop- eration of phenomenology and empirical science?}

In the following I will try to illustrate this fruitfulness in three areas: (a) embodiment, (b) time-consciousness, and (c) interpersonality.

\section{a) Embodiment}

Phenomenologists such as Merleau-Ponty [25], Straus [41] or Schmitz [37] have shown how our embodiment tacitly permeates all our experiences and bestows on them a sense of 'mineness'. Conscious experiences are thus essentially characterized by having a subjective 'feel' to them, a quality of 'what it is like' to have them [27]. This holds true not only for bodily experience itself, but for emotions, mood or even perceptions as well: There is something it is like to taste an apple, to feel the sand of a beach, to hear the rhythmic sound of a drum. Infant research has shown that the child's perception is permeated with bodily feelings and dominated by felt similarities of rhythm, intensity or tone. There is a primordial layer of a 'bodily felt sense', a "sensus communis" that precedes the separation of proprioception, perception and emotion [14].

This sense is also the phenomenal basis of interpersonal perception: We experience a similitude or resonance between the outward expressivity of others and our own bodily expressivity which in turn is in resonance with our emotional states. The body works as a „felt mirror“ of the others. It elicits a non-inferential process of empathic perception which Merleau-Ponty called "transfer of the corporeal schema" and which he attributed to a primordial sphere of "intercorporality" [26]. Infant research has confirmed this view by showing that even new-born babies are able to imitate facial expressions of others [23, 24]. By the mimetic capacity of their body, they also transpose the seen gestures and mimics of others into their own feelings. There is a sphere of embodied sensibility and mutual resonance which we all share from the beginning with others as embodied subjects.

This bodily mirroring is now supported by neurophysiology and its discovery of so called "mirror neurons" in the premotor cortex. These neurons discharge both when someone performs an action and when he observes a similar action by another individual [32, 33]. They seem to represent a system that matches observed events to similar, internally gen- 
erated actions, and in this way forms a link between the observer and the actor. This points to a neurobiological basis of mutual understanding, namely by mimetic or resonance behaviour, be it actual or only virtual.

These converging results from different research approaches are also highly important for psychiatric disorders, especially for schizophrenia. Growing evidence from phenomenologic as well as empirical research points out that the schizophrenic patient suffers from what may be called a disembodiment of experience [7, 10, 29]. He does not ,inhabit' his body any more, in the sense of using as taken-for-granted its habits or automatic performances in order to participate in the world. The tacit ,mineness ' of experience is undermined and an alienation of perception and action results. As Sass writes, "...the sense of self withdraws from what it had previously inhabited, and what had previous functioned as the very medium of our selfhood, comes to be experienced as external objects or alien objects rather than as the medium of our existence" [36]. In a similar way, Ronald Laing described what he called the 'disembodied self' in schizophrenia:

"Such a divorce of self from body deprives the unembodied self from direct participation in any aspect of the life or the world, which is mediated exclusively through the body's perceptions, feelings, and movements ... The unembodied self, as onlooker at all the body does, engages in nothing directly. Its functions come to be observation, control, criticism vis-à-vis what the body is experiencing and doing, and those operations which are usually spoken of as purely 'mental'. The unembodied self becomes hyper-conscious“ [19, p.71).

In order to compensate for the loss of automatic bodily performance, the patients have to prepare and release each single action consciously and deliberately, in a way that could be called a "Cartesian“ action of the soul on the body. It is no wonder that they often speak of a split between their mind and their body, of feeling hollowed out, like a marionette or a robot; for the sense of being alive depends on being an incarnated subject, with integrated bodily performances at one's disposal. In the same line, we find a disembodiment of perception in schizophrenia: Instead of simply perceiving the world, the subject, as it were, becomes witness to his own perceiving; hence the artificial or stage-like character of the environment in early schizophrenia [6, p.587f.].

This has consequences for interpersonal perception as well: There is a correlation between the disturbance of bodily self-perception and perception of expressive signals from others. Schizophrenic patients have 
marked difficulties in recognizing faces, in understanding facial expression and gestures, as has been shown in interaction analyses [2, 40]. At the same time, they often show a strong impairment of self-actualisation in bodily expression. The alienation of the intercorporal sphere that precedes any thematic verbal exchange led Kimura [18] to view schizophrenia in the last analysis as a disturbance of the "between" or the interpersonal atmosphere. It may also be tempting to speculate on, and search for, a neurobiological basis of this disturbance, concerning neuronal mirroring or resonance behavior, and its link to the bodily felt sense of self.

As we can see, phenomenology opens the access to a deeper layer of experience, here embodiment, that is disturbed in mental illness. My next example is

\section{2) Time Consciousness}

The basic temporal structure of consciousness was described by Husserl as an interweaving of retentions (= what has just taken place and still remains at the margin of the present experience), of presentations (= what is immediately present) and of protentions (= what is expected to be presented). Varela [43] has searched for neurological underpinnings of this subjective time-experience in nonlinear, dynamic systems theory; he used it as an example of the necessary cooperation of phenomenology and cognitive neuroscience, or of what he termed "neurophenomenology". I want to point to a possible application of Husserl's model to psychotic experiences, though here I can only touch briefly on this issue [cf. 13, p.144ff.].

The retentional-protentional structure of consciousness is essential for the temporal integration of the sequence of moments into "intentional arcs" [25, p.135f.]: e.g. to speak a meaningful sentence as well as to understand it depends on the continuous awareness of the words just spoken and on the anticipation of the words to come. The span of the intentional arc structures my field of awareness; it helps me to keep my speech on the track and to prevent unfitting ideas or words from intruding. At the same time, this temporal integration of single moments is the presupposition for the sense of one's own continuity or identity over time. I am not only aware of the sentence I speak but also of myself speaking it and intending it. There is a sense of mineness and of agency 
built into the retentional-protentional structure of consciousness. It is the carrier of the unity of the self over time.

Now let us assume a weakening or intermittent failure of this retentionalprotentional function in schizophrenia, i.e. a sudden discontinuity of consciousness. Then the constant intertwining of succeeding moments gets lost. All of a sudden, the anticipated goal of thoughts has vanished; for a moment, even the possibility of any future is abolished. This would be experienced as a kind of „blackout“ or, in the patient's language, as a thought withdrawal. However, as a result of this weakening or discontinuity of the intentional arc, the inhibition of unintended thoughts fails as well. Associations and ideas appear „out of the blue“ and interrupt the line of thoughts that the patient tried to draw. A thought occurring at this moment of discontinuity lacks the sense of mineness and agency. The intentional arc normally bestowing this sense on the thoughts is broken. Such unbidden thoughts intruding into one's mental activity are experienced as alien and inserted, or even as „voices“. The same may apply to motor impulses: A movement of my body that I did not anticipate appears as caused by someone else.

Schizophrenic experiences of reference, persecution and control may thus be conceived as an "inversion of intentionality": With the weakening and intermittent paralysis of the patient's own intentional activity, the direction of mental events now emerging is reversed and turned against him, as if coming from the outside. For thoughts or actions that cannot be fit into one's own intentional field, but remain as fragments, must appear to be derived from an alien, superior intentional power. The same applies to perception: since the schizophrenic patient may not actively and intentionally direct himself toward the world, everything in turn seems to aim at him. He becomes the passive center of the world: Instead of actively perceiving, thinking and acting, he is being perceived, ' being thought', and acted upon by others.

Thus from a phenomenological point of view, so-called "first rank symptoms" of schizophrenia may be derived from a disturbance of the temporal integration of consciousness, from a discontinuity of the self. Of course this is a very short outline of a theory that would have to be explained extensively and underpinned by evidence. A number of results from experimental psychopathology could be integrated into such a model. Thus Spitzer et al. [39], working with the semantic priming paradigm in schizophrenic patients with formal thought disorder, found a do- 
paminergic disinhibition of semantic networks with an extended scope of associations; that means, the patient's attention was not focused on a normal range of obvious associations, but highly distractable. This corresponds to a weakening of the intentional arc which lets unfitting ideas intrude in the line of thoughts. Impairment of the attentional span, disturbances of working memory or executive control functions mainly located in the prefrontal cortex may also be interpreted as contributing to a disintegration of the temporal unity of consciousness [44].

As we can see, phenomenology may provide a framework for the integration of cognitive research results into higher order concepts. On the other hand, it also puts a constraint against attempts to explain the psychotic experience only "bottom-up", i.e. by a simple increase of so-called basic disturbances that finally overburden the brain's capacity of information processing. Phenomenology, for its part, emphasizes the "transcendental" source of the psychotic alienation, namely in the highest and most complex functions of human consciousness.

\section{c) Interpersonality}

My final example concerns phenomena associated with perspective-taking in the interpersonal sphere. Laing [20] explored this sphere thoroughly and coined the term of "self-other-metaperspective", i.e. the ability to imagine other persons mental states, thoughts or feelings - today commonly put under the heading "theory of mind" [12, 45]. Laing also showed how this perspective-taking may spiral up on increasingly higher levels of complexity, according to the following pattern:

I am aware of you.

I am aware of your being aware of me.

I am aware of your being aware of me looking at you, etc.

Now this level of complexity apparently overburdens many psychotic patients. They may say for example:

„The consciousness of others intrudes upon me and lets my self vanish“ [16].

„When I look at somebody my own personality is in danger. I am undergoing a transformation and my self is beginning to disappear“ [8].

So instead of establishing a mutual understanding, the reciprocity of perspectives threatens the schizophrenic patient with a loss of his self. How can we explain this? - First we have to take into account that this meta- 
perspective is only a virtual one. Of course, when I am aware of your being aware of me, I do not become you; I do not lose my embodied being. Interpersonal perception implies a continous oscillation between the central, embodied perspective on the one hand, and the decentred or virtual perspective on the other. The German philosopher Plessner [31] coined the apposite term of man's "excentric position", meaning the dialectical integration of both perspectives.

This integration requires the fundamental ability of pretending, or in other words, a symbolizing or "as-if"-function that appears to be a central characteristic of the human mind. This function allows us to suspend the validity of the immediate experience, and to take it to be something other than itself: e.g. a mirror image, a map of the town, a traffic sign, etc. The "as-if-function" is also necessary for perspective-taking and mutual understanding: I have to put my body-centred existence into brackets and for a moment pretend to be in the other's place. However, in order not to lose myself in this oscillation, it is also necessary to keep up the tension and the difference between the embodied and the virtual perspective. Though this happens in every conversation, it is nevertheless a complex task that requires a high intentional effort.

A failure of the symbolizing function can be found in autistic children: They are usually impaired in representing mental states of others and in understanding pretend play (e.g. her mother using a banana as a telefone); they also confuse the personal pronouns which require a change of perspective (they may e.g. say: "you want biscuit” when they actually mean "I want a biscuit" [11, 21]). Moreover, autistic children are highly impaired in non-verbal understanding, i.e. in their bodily mirroring of others (cf. above). This, however, is the basis for the development of a "theory of mind" and the ability of perspective-taking. A person who is not able to use his body for imitating, mirroring and thus understanding other persons' behaviour will have difficulties on a symbolic level of understanding as well. Thus autism illustrates the narrow connection between bodily mirroring, development of the "as-if"-function and taking the other's perspective.

In schizophrenia, a failure of symbolization becomes apparent mainly in concretism, in the inability to interpret proverbs, or in the concretistic language of delusion. The tension between the symbolic and the concrete level of meaning cannot be kept up, and they are equated. For the same 
reason, perspective-taking in social situations threatens with loss of the self: The schizophrenic patient is caught in the decentred perspective and cannot maintain his own embodied center. The perspectives of self and other are confused instead of being integrated. This short-circuit of perspectives may lead to the experience of thought-broadcasting: All the patient's thoughts are known to others; there is no difference between his mental life and that of others any more.

It is for this reason that schizophrenia manifests itself often in situations of social exposure and emotional disclosure, when the affirmation of one's own intentionality against the perspective of the others is at stake: e.g. when leaving the parents ${ }^{6}$ home, starting an intimate relationship or entering into working life. In such situations, the patient may lose his embodied perspective and get entangled in an imaginary view of himself from the outside: Everyone seems to look at or spy on him, everything is meant for him; he becomes the defenceless object of anonymous intentions. His intentionality is not strong enough to keep up the tension between the embodied and the virtual perspective. Thus we find again what may be called a disembodiment, caused by a loss of self in the dialectical process of interpersonal perception.

Of course, this symbolizing function is the highest of the human mind, and there is no easy way to explore its neurobiological underpinnings. We may at least assume that different brain regions have to work in interconnection to allow this metarepresentational function to emerge. And one may speculate that it could finally be based on the mirroring function of the felt body in intercorporality which starts when the baby sees his mother for the first time. Interestingly, Vogeley [46] recently found different correlates of fMRI-activity when the first-person-perspective changes into taking the perspective of another person: Neural activity then changes from the right temporoparietal cortex (which is closely related to the body schema) to the left temporopolar cortex, while the anterior cingulate cortex is activated in both cases. There is also preliminary evidence for a disturbance of these activities in schizophrenic patients [45]. This remains an important question for further research. 


\section{Conclusion}

To conclude, I hope to have shown by these examples how the phenomenologic approach may contribute to psychiatric understanding and research. I finally want to quote Laing once more:

"... the theory of man as person loses its way if it falls into an account of man as a machine or as an organismic system of it-processes ... It seems extraordinary that ... an authentic science of persons has hardly got started by reason of the inveterate tendency to depersonalize or reify persons" [20, p.21].

Laing reminds us that psychiatry as a science is always in danger of depersonalizing the patient by viewing his behaviour and utterances only in terms of disturbed neuronal connections, transmitter imbalances etc. Phenomenology may be a possible remedy against this danger: a scientific attitude that takes subjectivity seriously and by the epoché seeks to find the common roots of experience that connect the psychiatrist and the patient even when there is a limit to mutual understanding on the symbolic level.

\section{References}

1. Andreasen NC (1991) Reply to "Phenomenology or Physicalism?" Schiz Bull 17: 187-189.

2. Berndl K, Cranach M, Grüsser OJ (1986) Impairment of perception and recognition of faces, mimic expression and gestures in schizophrenic patients. Eur Arch Psychiat Neurol Sci 5: 282-291.

3. Blankenburg W (1979) Phaenomenologische Epoché und Psychopathologie. In: Sprondel WM, Grathoff R (eds) Alfred Schuetz und die Idee des Alltags in den Sozialwissenschaften. Enke, Stuttgart, 125-139.

4. Blankenburg W (1991) Phänomenologie als Grundlagendisziplin der Psychiatrie. Fundamenta Psychiat 5: 92-101.

5. Blankenburg W (2002) First steps toward a psychopathology of common sense. Philosophy, Psychiatry and Psychology (in press).

6. Bovet P, Parnas J (1993) Schizophrenic delusions: A phenomenological approach. Schizophr Bull 19: 579-597.

7. Brewer Bill (1998) Bodily awareness and the self. In: Bermúdez JL, Marcel A, Eilan N (eds) The body and the self. MIT Press, 291-310. 
8. Chapman J (1966) The early symptoms of schizophrenia. Brit J Psychiat 112, 225-251.

9. Dennett DC (1991) Consciousness explained. Little, Brown, New York.

10. Eilan N, Marcel A, Bermúdez JL (1998) Self-consciousness and the body: An interdisciplinary introduction. In: Bermúdez JL, Marcel A, Eilan N (eds) The body and the self. MIT Press, 1-28.

11. Frith U, Morton J, Leslie AM (1991) The cognitive basis of a biological disorder: autism. Trends Neurosci 14: 433-438.

12. Frith U (1992) The cognitive neuropsychology of schizophrenia. Lawrence Erlbaum Associates, Hillsdale NJ.

13. Fuchs T (2000) Psychopathologie von Leib und Raum. Phaenomenologisch-empirische Untersuchungen zu depressiven und paranoiden Erkrankungen. Steinkopff, Darmstadt.

14. Fuchs $\mathrm{T}$ (2002) The tacit dimension. Commentary to Wolfgang Blankenburgs "First Steps Toward a Psychopathology of Common Sense". Philosophy, Psychiatry and Psychology (in press).

15. Gallagher S (1997) Mutual enlightenment: Recent phenomenology in cognitive science. J Consciousness Studies 4: 195-214.

16. Kant O (1927) Zum Verständnis des schizophrenen Beeinflussungsgefühls. Z ges Neurol Psychiat 111: 433-441.

17. Kaplan HI, Sadock BJ (1988) Synopsis of Psychiatry. $5^{\text {th }}$ ed. Williams \& Wilkins, Baltimore London.

18. Kimura B (1975) Schizophrenie als Geschehen des Zwischenseins. Nervenarzt 46: 434-439.

19. Laing RD (1960) The divided self. Tavistock, London.

20. Laing RD, Phillipson H, Lee AR (1966) Interpersonal perception. Tavistock, London.

21. Leslie A, German TP (1995) Knowledge and ability in theory of mind: one-eyed overview of a debate. In: Davies M, Stone T (eds) Mental simulation. Evaluations and applications. Blackwell, Oxford, 123-151.

22. Marazziti D, Cassano GB (1997) Neuroscience: Where is it heading? Biol Psychiat 41: 127-129.

23. Meltzoff A, Moore MK (1977) Imitation of facial and manual gestures by human neonates. Science 198: 75-78.

24. Meltzoff A, Moore MK (1989) Imitation in newborn infants: exploring the range of gestures imitated and the underlying mechanisms. Developmental Psychol 25: 954-962.

25. Merleau-Ponty M (1962) The phenomenology of perception. Transl. by C. Smith. Routledge \& Kegan Paul, New York.

26. Merleau-Ponty M (1988) Résumé de cours à la Sorbonne 1949-1952. Grenoble.

27. Nagel T (1974) What is it like to be a bat? The Philosophic Review 83: 435-450.

28. Ochsner KN, Lieberman MD (2001) The emergence of social cognitive neuroscience. Am Psychol 2001 56:717-34.

29. Parnas J (2000) The self and intentionality in the pre-psychotic stages of schizophrenia. A phenomenological study. In: Zahavi D (ed) Exploring the self. John Benjamins, Amsterdam Philadelphia, 115-147. 
30. Parnas J, Bovet P (1995) Research in psychopathology: epistemologic issues. Compr Psychiat 32: 1-15.

31. Plessner H (1975) Die Stufen des Organischen und der Mensch. De Gruyter, Berlin.

32. Rizzolatti G, Fadiga, L, Gallese V, Fogassi L (1996) Premotor cortex and the recognition of motor actions. Brain Res Cogn Brain Res 3: 131-141.

33. Rizzolatti G, Luppino G, Matelli M (1998) The organisation of the cortical motor system: new concepts. Electroencephal Clin Neurophysiol 106: 283-296.

34. Rorty R (1979) Philosophy and the mirror of nature. Princeton Univ. Press.

35. Sadler JZ (1992) Eidetic and empirical research: A hermeneutic complementarity. In: Spitzer M, Uehlein FA, Schwartz MA, Mundt C (eds) Phenomenology, language and schizophrenia. Springer, Berlin Heidelberg New York, 103-114.

36. Sass L (2000) Schizophrenia, self-experience, and the so-called "negative symptoms". Reflections on Hyperreflexivity. In: Zahavi D (ed) Exploring the self. John Benjamins, Amsterdam Philadelphia, 149-182.

37. Schmitz H (1965) System der Philosophie. Vol. II/1: Der Leib. Bouvier, Bonn.

38. Schwartz MA, Wiggins OP (1992) The phenomenology of schizophrenic delusions. In: Spitzer M, Uehlein FA, Schwartz MA, Mundt C (eds) Phenomenology, language and schizophrenia. Springer, Berlin Heidelberg New York, 305-318.

39. Spitzer M, Weisker I, Maier S, Hermle L, Maher BA (1994) Semantic and phonological priming in schizophrenia. J Abnorm Psychol 103: 485-494.

40. Steimer-Krause E, Krause R, Wagner G (1990) Interaction regulations used by schizophrenic and psychosomatic patients: studies on facial behavior in dyadic interactions. Psychiatry 53: 209-228.

41. Straus E (1956) Vom Sinn der Sinne. Springer, Berlin Göttingen Heidelberg.

42. Varela FJ (1996a) Neurophenomenology. A methodological remedy for the hard problem. J Consiousness Studies 3: 330-349.

43. Varela FJ (1996b) The specious present: A neurophenonemology of nowness. In: Petitot J, Roy JM, Pachoud B, Varela FJ (eds) Naturalizing phenomenology: Contemporary issues in phenomenology and cognitive science. Stanford Univ. Press, 266-314.

44. Vogeley K, Kurthen M, Falkai P, Maier W. (1999) Essential functions of the human self model are implemented in the prefrontal cortex. Conscious Cogn 8: 343-63.

45. Vogeley K, Bergmann A, Schneider-Axmann T et al. (2002) Neural Correlates of Theory of Mind and Self-Perspective in Schizophrenia (submitted, personal communication).

46. Vogeley K, Bussfeld P, Newen A, et al. (2001) Mind reading: neural mechanisms of theory of mind and self-perspective. Neuroimage 14:170-81.

47. Wiggins O, Schwartz MA, Spitzer M (1992) Phenomenological/descriptive psychiatry: The methods of Edmund Husserl and Karl Jaspers. In: Spitzer M, Uehlein FA, Schwartz MA, Mundt C (eds) Phenomenology, language and schizophrenia. Springer, Berlin Heidelberg New York, 46-69.

48. Zahavi D, Parnas J (1998) Phenomenal consciousness and self-awareness: A phenomenological critique of representational theory. J Consciousness Studies 5: 687-705. 


\section{Author's address:}

Thomas Fuchs, M.D., Ph.D.

Psychiatric Department

University of Heidelberg

Voßstr. 4

D-69115 Heidelberg

e-mail: Thomas_Fuchs@med.uni-heidelberg.de 